\title{
The concept difference between a major sports country and a world sports power of China and the development of China's
}

\author{
Yuan ZHANG \\ Weifang University of Science and Technology \\ Shouguang,Weifang,Shandong, 262700 China
}

\begin{abstract}
What is the concept of a major sports country and a world sports power and the difference lies. In the case of the current debate, the concept of sporting nation and sports power, such as the difference from a proposal to explore the proposition has a relatively strong "China complex." "A major sports country and a world sports power" can be understood as two words in a particular historical context and the social and cultural needs of the environment, is the case in recent years, China's athletics at the Olympics and other world competitions obtained good results for China. The overall concept of the level of development of sports and the overall strength of the proposed development prospects under the background of the future. Dialectical unity between a major sports country and a world sports power will objectively and scientifically analyze the development stage and the career goal of our sport, will help to mobilize all positive factors for building a harmonious society, for making the necessary theoretical preparation to promote the comprehensive development.
\end{abstract}

Keywords- a major sports country; a world sports power; Development

\section{INTRODUCTION}

Tian Yupu come up that it is a common feature of a big country to make the Competition of Olympic gold medal as a symbol and sign of big country sports. A necessary condition to judge a major sports country is: sports population, Olympic sports scores and gross domestic industry proportion of gross domestic product, these three aspects.

Zhou Liping, Tian Yupu come up, a world sports power is reflected in the overall strength of a country's and overall level of sports development. Although there is no uniform international evaluation criteria of a world sports power but on this stage, to become the world sports power there remains three necessary conditions to fit in: Sports: the total number of medals and a total score of Olympic Games ranking in first eight; mass sports: adults above 20 years of age in the sports population accounts for more than $45 \%$; sports industry: GDSP more than the proportion of $1.5 \%$ of GDP.

The difference between a major sports country and a world sports power

Zhou Liping and Tian Yupu had made a discrimination and analysis about a major sports country and a world sports power: a major sports country should be a comprehensive sports category. "Big" is relatively "small" in comparison. Mainly from the number, size, area, volume, etc. to measure. More specifically refers to the capacity of physical activity possession, more space, wider area, the number of people participating in sports activities more wider scope. A major sports country refers to the a wide range of sports project, a large number of the population to participate in sports, a large-scale sports facilities, the countries that have greater influence on the world of sports . A world sports power is a relative concept, is an quantitative anarchically evaluation about country's overall level of sports, the number of national sports, size, structure, composition, qualitative organization

And quantitative evaluation. A world sports power refers to the countries whose overall strength of the sports' superior development; overall levels were significantly higher than in other countries. Among them, the sports score is the basic standards to measure a world sports power. However, A world sports power is the manifestation of a national sports development and the overall strength of the overall level, it is the soft power of sports, mass sports, school sports and other hard conditions and physical culture, sports philosophy, sports and technology.

Relationship between a major sports country and a world sports power is a dialectical unity. From the literal sense, a major sports country focuses on highlighting the "big" number, large scale, is to ask the "quantity", emphasizing the sporting consciousness, popular sports facilities, update sports concept. While a world sports power focusing on "quality" is, sports industry flourished and supply of sports products are adequate. A major sports country and a world sports power in line with the quality of mutual change law, are different stages of the development process of sports, is representation concept of sports at different times at different levels at different stages of development. A major sports country and a world sports power have a dynamic association, the "big but not strong" and "strong but not great" is not perfect.

Zhou Liping, Tian Yupu conducted from competitive sports, mass sports field, stadium construction scale shows three aspects: our sports development adapt to economic and social development of the country and the development of sports is also very fast, we can be termed a major sports country But I believe that the definition of a standard a major sports country such as competitive sports, mass sports field, stadium construction scale, the gross domestic sports industry to gross domestic product (GDP) should be studied from China's specific conditions.

From competitive sports, the yellow man known in terms of flexibility but a little lacking in the explosive. So we can get "dream team" of winning in gymnastics, but only Liu Xiang succeeds in the track and field, making a miracle. In table tennis, badminton and other fields have 
deep mass base and secure nationwide system. Our country is undoubtedly the leader in the field of sports. Gross domestic sports industry in gross domestic product (GDP) terms as Chinese sports market industrialization walking time soon, sports market is not mature, perfect. So the percentage of gross domestic sports industry in gross domestic product (GDP) is relatively low.

In the field of mass sports because of the different sports recognized standards and evaluation criteria vary. Sport is an important indicator of a reflection of the level of mass sports of a country's population. 2008, the survey data of State Sports General Administration shows that 2007 China's urban and rural residents whose age over 16 the number of regular physical activity accounted for $28.2 \%$. Our standards are at least three times a week to participate in a 30 minutes of moderate-intensity physical activity, but for a long time, we have identified the field of sports has a deep background of West, especially after the Opium War, "the new Western sports" became the sole criterion of sport, while Chinese traditional sports fitness items are excluded from the sports circles. Such as the well-known "Sword

Bridge and Oxford rowing "movements make the" dragon boat" a custom. In fact, the ancient Olympic Games are developing from the ritual of the festival athletic activities become athletic games.

Of course, the form of Western sports represents the direction of the trend of world sports development, has played a good role model in China's sports development. But we should have a choice in the draw, to comply with China's national conditions. Such as the development of tennis and equestrian events because there is no mass base in China is not only develop difficult and cast intensive capital, venues amazing, and therefore to carry out a mass movement on the convergence work to do. When not use for reference, absorbing foreign advanced all cultural achievements, including sports, including in the form of a simple disjunctive proposition to introduce incompatible answer or the other, the two are incompatible. Thereby artificially make "China - the West", "backward advanced" opposition. China currently undertaken square cultural activities and rural social customs loved Tai Chi, dragon and lion dances, Younger, kites, fan dance, percussion and other "mass sports" in the entertainment, while serve to improve the prevention and also treat of diseases of national quality sports features.

The goal of construction of a world sports power is to further establish the people-centered development concept for the development of sport to build a harmonious society. The fundamental purpose is to promote the development of sports round human development and social harmony and progress. Establish the scientific concept of development in sports work, work on the base point on people-oriented, is to care for people, respect for people, free for people, develop people as the foundation for sports development. This is also the basis of the value and the power source of sports development. Only really achieve, maintain the most fundamental interests of the majority of sports development and good actors, the main sports development will not missing, power will not fail. Sustainable development of sports undertakings will have a fundamental guarantee. Conversely, if the work is not a true sports-based people-oriented, sports will change into an alienation tool, shrine worships money and become ignore people, bound man, twisted people, destroy people's means, which come to its primitive negative value, lost power and the development of the reasons that exist in modern society. Therefore, sports development must reflect the people-centered development philosophy and building a socialist harmonious society and adapt to society.

\section{THE GOALS AND TASKS OF A WORLD SPORTS POWER'S DEVELOPMENT}

Promote a world sports power forward, is the State Council based on the primary stage of socialism's basic national conditions, put forward by summarizing the development of China's sports practice, learning from the experience of foreign sports development, adapting to the new requirements of the times. It is China's sports development strategy fully completed in 2020 with the well-off society and from the middle to this century and goals consistent with achieve the great rejuvenation of the historical process this century. Building a world sports power goal is to basically complete working sports power system and business architecture, the initial realization of modernization of China's sports in 2020 ; this mid-century fully complete the task of building a world sports power, the full realization of China's modern sports

Technology. Around building a world sports power goal, by mid-century, China must strive to accomplish the following sports main tasks:

\section{A. full completion of the work to create the characteristics of China's sports development path, providing Chinese experience for the world of sports development}

How the world's largest developing country to achieve modernization sports, is an unprecedented great practice. To be a comprehensive summary of new China in sports, especially since the reform and opening up, on the foundation of the successful experience of sports development, further reform and improve the government's co-ordination of government-led, government-backed sports management system, to further explore and improve the social organization, market organization and broad participation of the people operating mechanism, establish and improve government guaranteed public sports service system for mass sports, government-backed National Sports System and the government encourage and guide the development of mechanisms for the sports industry, leading a sports development road after taking a hair of innovation for the world powered sports system evolution and development of civilization. 
B. fully complete the mass sports work system peopleoriented, integrated into the national, active and healthy lifestyle

Establish the urban and rural fitness service system, and continuously improve the level of government to protect citizens' basic physical needs, the capital that the government invested in mass sports, mass sports organization level, the proportion of people who participate in regular physical activity, and the average cover of the stadium, the quantity and quality of community sports Instructor (volunteer team) and other indexes reached or exceeded moderately developed countries, physical activity has become the first choice of national fitness leisure.

\section{Building a new pattern with a solid foundation, $a$ balanced development, a outstanding core sports}

Adhere to reform and improve the nationwide system of competitive sports, the use of international and domestic resources and markets to further expand and reinforce the foundation of talent and base sports items; maintain advantages of the project, strengthen the latent advantages of the project, focusing on the development large items based on athletics and tourism and the collective ball games as the representative of the basket ball and volleyball; keep leading in the Summer Olympic Games gold medal, medals, three out of the previous stable, continuous breakthroughs in the Winter Olympics, the overall level ranks in the advanced gold medal, medals, score the top six; significantly enhance the technical level of football, to sustain, stable access to the competitive right to participate in the World Cup and the Olympic Games, basketball and volleyball to reach the world advanced level (before the World Championships and Olympic Games top 6 ); strive successful bid to host 2020 World Cup, once again host the next Summer Olympics in 2050; steady develop the professional sports, group projects focus on the development of table tennis, badminton, football, basketball, volleyball league, focusing on the development of personal projects martial arts, tennis, golf, boxing, billiards, chess; cultivate and foster a number of world influence of sports stars and sports brand events.

\section{D. to create sports industry with a comprehensive strength, wide range, international influence.}

By continually expand the open, deepening reform and institutional mechanisms for the elimination of barriers restricting the development of sports industry, to develop the sports industry as the basis, to seize the city, young people and the middle class this three priorities, establish and improve sports competition market covered the whole society, the coexistence of high middle and low mass fitness entertainment market, with professional leagues and various commercial competition, performing as the main, driven by sports agency, sports media, sports exhibitions, sports tourism, sports and cultural creativity, sports equipment manufacturing and sales The all-round development. By 2020 the proportion of the number of employees increase to the value of the country's GDP, the sports industry and sports industry accounts for the proportion of employment both increase to $1 \%$, to 2050 , both of these two indicators reached 2.5 percent; in all areas of the sports industry is to create a internationally competitive sports business group, while the formation of a group with global influence of sports race brands, sports enterprise brand and sports products brands, share that sports account for trade services global market has been increasing.

\section{E. Building a vibrant, unique charming Chinese sports culture}

A major sports nation transform into a world sports power must be accompanied by the thriving Chinese sports culture. Competition between sports power in the world today, is largely competition of sports and cultures' charm. We should place develop sports culture as a breakthrough, and comprehensively promote the construction of sports culture, leading the development of various sports science from the height of culture and harmonious development. To attach great importance to the mining, sorting, protection and utilization of Chinese traditional sports culture, making it compatible with contemporary society, in harmony with modern civilization, keep its national character, reflecting the times. To further strengthen international exchanges of Chinese sports culture, using the modern technology to develop, use and dissemination of national folk sports and cultural resources. Martial arts and traditional cultivation exercises, to become an important part of Chinese Culture Year and the Confucius Institute held abroad, and improve the Chinese sports culture's influence in the global.

\section{CONCLUSIONS}

From a major sports country to a world sports power, is a historic leap sports development in China, but also has a new sports front starting line along the road of socialism with Chinese characteristics to forge ahead. Sports workers should unite more closely together, thoroughly implement the scientific concept of development, strong faith, forge ahead, modest, hard, hard in the development of sport and create greater glory for national body, the party, the motherland and the people to win more honors, make greater contributions for the construction of Chinese characteristics socialism!

\section{References}

[1] Wu Yan, Discussion sporting nation and sports power [J]. Science and Education Guide (in Xunkan), 2010,05: 133-134.

[2] Kong Wei, Zhang Xiya. On the core values of a world sports power [J]. Ji Ning University, 2012,03: 87-92.

[3] Liu Meiying, Review and Prospect about a world sports power[J]. Sports Adult Education, 2012,06: 39-42 + 45 .

[4] Tian Yupu, Efforts to achieve a major sports power forward from the world sports power [J]. Sports Science, 2009,03: 3-8

[5] Bao Mingxiao, Strategy research on achieve a major sports power forward from the world sports power [J]. Nan Jing Institute of Physical Education (Social Sciences), 2009,06: 1-6.

[6] Han Dong, The speculation between a major sports nation and a world sports power- The shift of China from a major sports nation to a world sports power[J]. Contemporary Sports Science, 2014,01: 116-117. 